\title{
MODELING AND OPTIMIZATION OF FACE MILLING PROCESS PARAMETERS FOR AISI 4140 STEEL
}

\author{
Gokhan BASAR, Hediye KIRLI AKIN, Funda KAHRAMAN, Yusuf FEDAI
}

\begin{abstract}
In this study, the effect of cutting parameters such as the depth of cut, feed rate, cutting speed and the number of inserts on surface roughness were investigated in the milling of the AISI 4140 steel. The optimal control factors for surface quality were detected by using the Taguchi technique. Experimental trials were designed according to the Taguchi $\mathrm{L}_{18}\left(2^{1} \times 3^{3}\right)$ orthogonal array. The statistical effects of control factors on surface roughness have been established by using the analysis of variance (ANOVA). Optimal cutting parameters were obtained by using the $S / N$ ratio values. The ANOVA results showed that the effective factors were the number of inserts and the feed rate on surface roughness. However, the depth of cut and the cutting speed showed an insignificant effect. Additionally, the First-order and Second-order regression analysis were conducted to estimate the performance characteristics of the experiment. The acquired regression equation results matched with the surface roughness measurement results. The optimal performance characteristics were obtained as a $0.5 \mathrm{~mm}$ depth of cut, $0.08 \mathrm{~mm} / \mathrm{rev}$ feed rate, $325 \mathrm{~m} / \mathrm{min}$ cutting speed and 1 number of inserts by using the Taguchi method. Additionally, the confirmation test results indicated that the Taguchi method was very prosperous in the optimization of the machining parameters to obtain the minimum surface roughness in the milling of the AISI 4140 steel.
\end{abstract}

Keywords: AISI 4140 steel; milling; regression analysis; surface roughness; Taguchi method; variance analysis

\section{INTRODUCTION}

The metal cutting process is defined to remove the unwanted material from the metal parts by using a cutting tool. Materials were moved by a conventional chip forming process such as milling, drilling, boring, turning in the manufacturing industry $[1,2]$. The milling process is one of the most significant metal removal processes in the traditional metal cutting operations.

The surface quality is a significant factor to appraise the productivity of both the mechanical parts and machined components. Hence, it is a very crucial measurement of the product quality. Surface quality is usually concerned with surface roughness. The surface roughness of the machine elements is understood to have a prominent influence on certain properties such as increasing the tribological properties of materials, wear resistance, fatigue strength, heat conduction, electrical conductivity, corrosion resistance and aesthetic appearance. However, it can also lead to increased production costs [3-5].

Nowadays, there have been numerous study advancements in the surface roughness modeling and the optimization of the performance of the manufacturing technologies. In order to produce a desired surface finish and to reach the greatest productivity of machining, cutting parameters should be chosen appropriately [6].

Regarding past research, surface roughness was examined in distinct research studies in which the experimental results, the mathematical models and statistical methods were assimilated. For instance, Filho et al. [7] studied the experimental numerical model of roughness in the finishing face milling of the AISI 4140 hardened steel. They applied the central composite design to optimize the cutting factors such as the cutting speed, feed and cutting depth in the end milling when machining the AISI 4140 steel with a CBN (cubic boron nitride) tool. The feed per tooth had a statistical prominent factor affecting the average surface roughness in the face milling. Ventura et al. [8] researched the machinability of the hardened AISI 4140 steel when turning with varied micro geometries. It is shown that the cutting edge micro geometry largely influences the feed and passive force components, whereas the cutting force, specific energy and cutting temperature are not strongly changed. Sales et al. [9] conducted the external vegetable oil-based minimum quantity cutting fluid in the milling of the AISI 4140 steel with a TiAlN coated cemented carbide insert. The minimum quantity fluid application supplied usually decreases the tool wear rate and as a result enhances tool life. Ozek et al. [10] used the Fuzzy logic to investigate the effect of the machining factors on the plasma arc machining process of the AISI 4140 steel. The fuzzy logic model was developed to predict the surface roughness. Results showed that the cutting speed had the statistical importance on the performance characteristic, whereas the plasma arc current had the least importance. Kivak and Cetin [11] performed the Taguchi method and regression analysis to identify the machinability of the 15-5 PH Stainless steel with the PVD TiAlN-AlCrO and $\mathrm{CVD}$ TiCN- $\mathrm{Al}_{2} \mathrm{O}_{3}$-TiN-coated carbide-cutting-tool inserts. It was observed that feed rate was a maximum contribution to surface roughness, whereas the depth of cut was a maximum contribution to the cutting force. Sarıkaya et al. [12] researched the effects of machining factors such as the cutting speed, feed rate and the number of cutting inserts on surface roughness and tool life in the face milling process of the AISI D3 steel with carbide coated inserts by using the Taguchi design technique. The experimental results presented that the number of cutting inserts was the most significant parameter affecting surface roughness, while cutting speed was the most significant parameter affecting tool life. Motorcu et al. [13] machined the AISI 4140 steel with a tungsten carbide cutting tool on a lathe. 
They investigated the effect of the depth of cut, the cutting speed and feed rate on the formation on surface roughness, the tool temperature and the tool-chip interface temperature by using the Taguchi method. Predictive models were developed to estimate the output performance characteristics by using the regression analysis. Ekici et al. [14] examined effects of wire speed, pulse on time and pulse off time on the material removal rate and surface roughness during the wire electrical discharge machining (WEDM) operation of the $\mathrm{Al} / \mathrm{B}_{4} \mathrm{C} / \mathrm{Gr}$ reinforced hybrid material by using the Taguchi technique and Response Surface Methodology. It was eventually detected that the most important parameter for the material removal rate is the wire speed, while for surface roughness the most dominant parameter is pulse on time. Gupta et al. [15] studied the effects of machining parameters such as the cutting speed, feed rate and distinct cooling conditions on a cutting force and surface roughness in the turning of the AISI 4340 steel by using the uncoated carbide insert. The Taguchi technique and the utility concept were used for the determination of the optimal performance characteristics simultaneously. They found that the cooling condition has a dominant effect on the performance characteristics. Kivak [16] researched the effects of machining parameters (cutting tools, cutting speed and feed rate) on surface roughness and flank wear by the aid of the Taguchi design technique in the dry milling of Hadfield steel. It was determined that in surface roughness, the most effective parameter is feed rate, while for flank wear, the cutting speed was the most powerful parameter. Ekici et al. [17] explored the influences of the cutting factors (wire tension, reinforcement percentage, wire speed, pulse-on time and pulse-off time) on the material removal rate and surface roughness in the WEDM process of the $\mathrm{Al} / \mathrm{B}_{4} \mathrm{C}$ composites produced via the hot pressing method by using the Taguchi method. The variance analysis results indicated that the dominant factor for the material removal rate is wire speed, while for surface roughness the most effective factor is pulse on time.

In this paper, the modeling and optimization of cutting parameters on surface roughness in the milling process of the AISI 4140 steel were researched by using the Taguchi technique and regression analysis. The furthest machining factors on surface roughness were conducted by using the analysis of the signal to noise $(\mathrm{S} / \mathrm{N})$ ratio and analysis of variance (ANOVA). The predictive equations were descended from the regression analysis to acquire the optimal surface roughness as a function of the milling parameters. Hence, the experimental and regression analysis results were compared with each other.

\section{MATERIALS AND METHODS}

The milling tests were conducted in dry cutting conditions by using a SPINNER MVC1000 model CNC milling machine equipped with a maximum spindle speed of $10000 \mathrm{rpm}$. The experimental set up is displayed in Fig. 1. The dimensions of the workpiece were $260 \times 150 \times 25 \mathrm{~mm}$. Before the tests started, the steel bulks were ground to remove the reverse effects of any surface disturbance. The milling tests were carried out at two depths of cut $(0.5$ and $1 \mathrm{~mm})$, three feeds $(0.08,0.12$ and $0.16 \mathrm{~mm} / \mathrm{rev})$, three cutting speeds $(175,250$ and $325 \mathrm{~m} / \mathrm{min})$ and three numbers of cutting inserts (1,2 and 3 piece). The milling process was applied by using a R 390-020B20-11M tool holder and a TiAlN+TiN, PVD-coated, R 390-11 T308M-PM 1030 solid carbide insert. In the milling tests, only one insert was used to minimize the effect of the tool tip run out on tool wear. The quality of a cutting surface is generally identified by the surface roughness and it is measured offline after the surface is cutting. After the milling tests, the average surface roughness $(R a)$ of workpieces was measured by the MITUTOYO SJ-400 transportable surface roughness tester. The cut off length and evaluation length were constant at $0.8 \mathrm{~mm}$ and $4 \mathrm{~mm}$ respectively. The measurement of surface roughness was carried out on a machined surface from three distinct points. The average value of the measurements was taken into evaluation to analyze the surface roughness attitude. Surface roughness measurements are illustrated in Fig. 2.
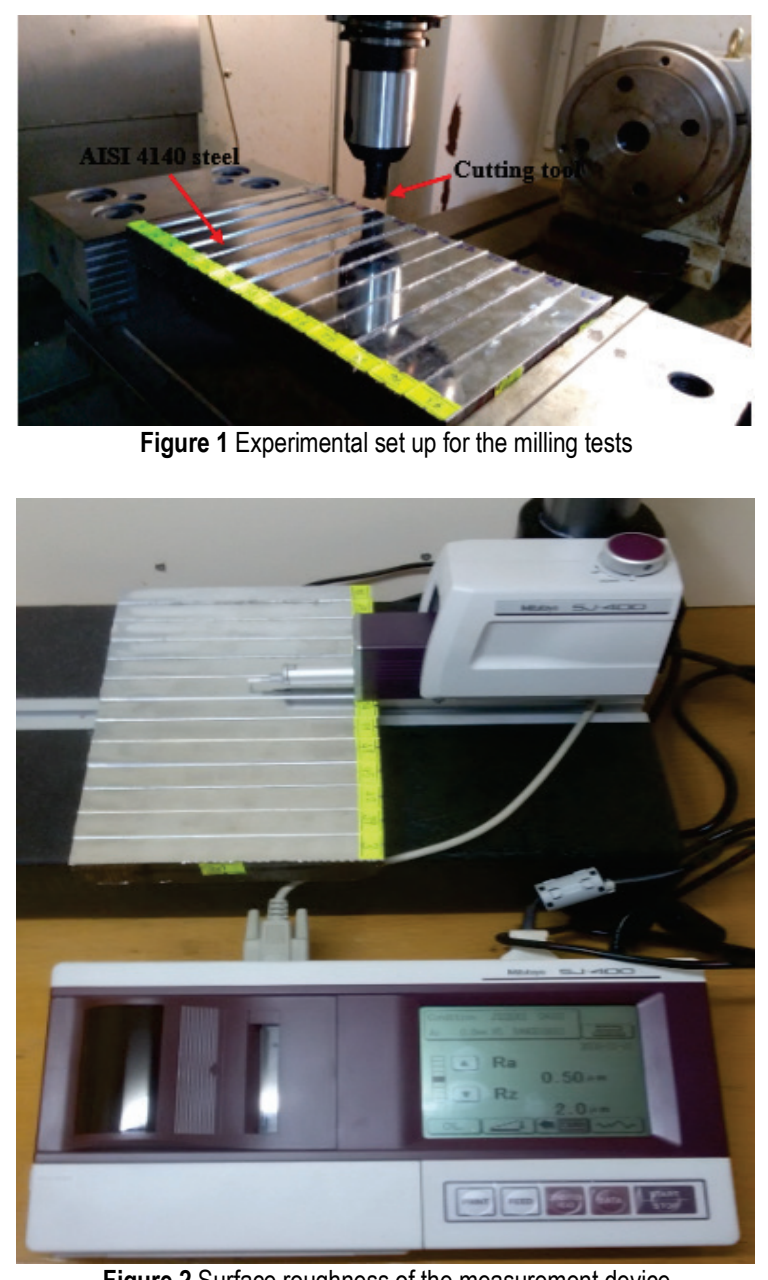

Figure 2 Surface roughness of the measurement device

The depth of cut ap (mm), feed rate $f(\mathrm{~mm} / \mathrm{rev})$, cutting speed $V(\mathrm{~m} / \mathrm{min})$ and number of inserts $N$ (pieces) were chosen as the control factors for surface roughness and their levels were detected as demonstrated in Tab. 1. The 
Taguchi $\mathrm{L}_{18}$ mixed orthogonal design matrix was conducted for performing the experiments.

\begin{tabular}{|c|c|c|c|c|c|}
\hline \multirow{2}{*}{ Parameters } & \multirow{2}{*}{ Unit } & \multirow{2}{*}{ Notation } & \multicolumn{3}{|c|}{ Level of factors } \\
\hline & & & 1 & 2 & 3 \\
\hline Depth of cut & $\mathrm{mm}$ & $a p$ & 0.5 & 1 & - \\
\hline Feed rate & $\mathrm{mm} / \mathrm{rev}$ & $f$ & 0.08 & 0.12 & 0.16 \\
\hline Cutting speed & $\mathrm{m} / \mathrm{min}$ & $V$ & 175 & 250 & 325 \\
\hline Number of inserts & piece & $N$ & 1 & 2 & 3 \\
\hline
\end{tabular}

\section{ANALYSIS AND EVALUATION OF EXPERIMENTAL} RESULTS

\subsection{Taguchi Analysis}

The Taguchi method is a strong design tool and it is extensively used in engineering problems. Furthermore, it considerably decreases the quantity of experiments using the orthogonal design matrix and reduces the influence of factors that cannot be controlled. Moreover, it ensures an easy, productive and systematical approach to indicating the optimal machining conditions for the manufacturing industry $[18,19]$. The Taguchi technique uses a loss function to compute the deviation between the test values and the willed values. This loss function is also turned into a signal-noise $(S / N)$ ratio [20].

Table 2 Experimental results and the $\mathrm{S} / \mathrm{N}$ ratios for $R a$

\begin{tabular}{|c|c|c|c|c|c|c|}
\hline Trial run & $a p$ & $f$ & $V$ & $N$ & $R a(\mu \mathrm{m})$ & $\mathrm{dB}(S / N)$ \\
\hline 1 & 0.5 & 0.08 & 175 & 1 & 0.183 & 14.7510 \\
\hline 2 & 0.5 & 0.08 & 250 & 2 & 0.230 & 12.7654 \\
\hline 3 & 0.5 & 0.08 & 325 & 3 & 0.497 & 6.0729 \\
\hline 4 & 0.5 & 0.12 & 175 & 1 & 0.220 & 13.1515 \\
\hline 5 & 0.5 & 0.12 & 250 & 2 & 0.273 & 11.2767 \\
\hline 6 & 0.5 & 0.12 & 325 & 3 & 0.730 & 2.7335 \\
\hline 7 & 0.5 & 0.16 & 175 & 2 & 0.443 & 7.0719 \\
\hline 8 & 0.5 & 0.16 & 250 & 3 & 1.100 & -0.8279 \\
\hline 9 & 0.5 & 0.16 & 325 & 1 & 0.140 & 17.0774 \\
\hline 10 & 1.0 & 0.08 & 175 & 3 & 0.397 & 8.0242 \\
\hline 11 & 1.0 & 0.08 & 250 & 1 & 0.213 & 13.4324 \\
\hline 12 & 1.0 & 0.08 & 325 & 2 & 0.220 & 13.1515 \\
\hline 13 & 1.0 & 0.12 & 175 & 2 & 0.367 & 8.7067 \\
\hline 14 & 1.0 & 0.12 & 250 & 3 & 0.660 & 3.6091 \\
\hline 15 & 1.0 & 0.12 & 325 & 1 & 0.143 & 16.8933 \\
\hline 16 & 1.0 & 0.16 & 175 & 3 & 1.097 & -0.8041 \\
\hline 17 & 1.0 & 0.16 & 250 & 1 & 0.270 & 11.3727 \\
\hline 18 & 1.0 & 0.16 & 325 & 2 & 0.633 & 3.9719 \\
\hline
\end{tabular}

The smaller-is-better, the-nominal-best and the largeris-better approaches are established considering the results of the $S / N$ ratio. The objective of this research was to reduce the surface roughness. For this reason, the smaller-the-better quality characteristic was used as presented in the Eq. (1) and listed in Tab. 2. The average of the $S / N$ ratio for each level of the machining parameters is calculated and given in Tab. 3. The graph of the mean of the $S / N$ ratios versus the factor levels is shown in Fig. 3.

$$
\frac{S}{N}=-10 \log \left(\frac{1}{n} \sum_{i=1}^{n} y_{i}^{2}\right)
$$

where $y_{i}$ is the $i^{\text {th }}$ measure of the actual test data in a run and $n$ is the number of measurement in each experimental test [21].

Table 3 Results of the $\mathrm{S} / \mathrm{N}$ ratios (dB) for $R a$

\begin{tabular}{|c|c|c|c|c|}
\hline Level & $a p$ & $f$ & $V$ & $N$ \\
\hline 1 & $\mathbf{9 . 3 4 1}^{*}$ & $\mathbf{1 1 . 3 6 6}^{*}$ & 8.484 & $\mathbf{1 4 . 4 4 6}^{*}$ \\
\hline 2 & 8.706 & 9.395 & 8.605 & 9.491 \\
\hline 3 & - & 6.310 & $\mathbf{9 . 9 8 3}^{*}$ & 3.135 \\
\hline Delta & 0.635 & 5.056 & 1.500 & 11.312 \\
\hline Optimal level
\end{tabular}

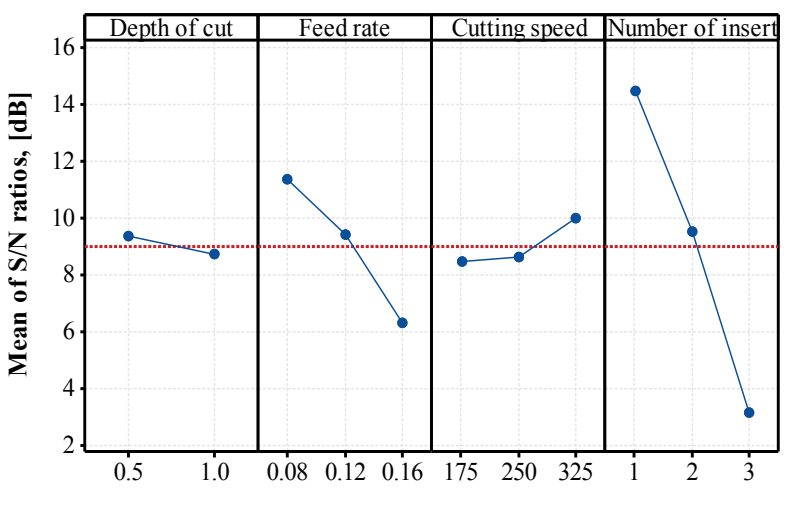

Signal-to-noise: Smaller is better

Figure 3 Mean $\mathrm{S} / \mathrm{N}$ ratio graph for $\mathrm{Ra}(\mathrm{dB})$

In this paper, ANOVA was employed to analyze the influence of the depth of cut, feed rate, cutting speed and number of inserts on surface roughness. The objective of ANOVA is to establish how the process parameteres affect the quality characteristics [22, 23]. This analysis was conducted for a confidence level of $95 \%$. The surface roughness is conducted to detect the utmost effect factor in the machining parameters by ANOVA. In the machining process, cutting parameters have an important effect in the experimental results. The ANOVA results for surface roughness are presented in Table 4 . The number of inserts was determined as an important factor since its $p$ value is less than 0.05 .

Table 4 ANOVA results for $R a$

\begin{tabular}{|c|c|c|c|c|c|c|}
\hline Source & DF & Adj SS & Adj MS & F & P & $\%$ PC \\
\hline$a p$ & 1 & 0.00188 & 0.001881 & 0.08 & 0.783 & 0.12 \\
\hline$f$ & 2 & 0.32588 & 0.162938 & 6.92 & 0.013 & 21.16 \\
\hline$V$ & 2 & 0.01481 & 0.007404 & 0.31 & 0.737 & 0.96 \\
\hline$N$ & 2 & 0.96237 & 0.481183 & 20.44 & 0.000 & 62.48 \\
\hline Error & 10 & 0.23538 & 0.023538 & & & 15.28 \\
\hline Total & 17 & 1.54031 & & & & 100 \\
\hline
\end{tabular}

As a result of the appraisal of surface roughness, the percentage contributions of process parameters for $a p, f, V$ and $N$ were defined as $(0.12,21.16,0.96$ and $62.48 \%)$, respectively, and the error was $15.28 \%$. Hence, it was discovered that the number of cutting inserts and the feed rate are more important than the cutting speed and the depth of cut concerning the surface roughness in milling the AISI 4140 steel.

The ANOVA analysis result declares that the number of inserts is the most important effect on surface roughness 
with a percentage contribution of $62.48 \%$. Moreover, the feed rate had a considerable influence on surface roughness with a percentage contribution of $21.16 \%$. However, the depth of cut and the cutting speed proved to be an insignificant factor on surface roughness.

The result obviously indicates the influence of the number of inserts on surface roughness in milling the AISI 4140 steel whose vibration produced a sophisticated frequency between the cutting tool and the workpiece with the enhancement number of the cutting insert. The other variable that has an effect on $R a$ is the feed rate with 21.96 $\%$. It is clear that increasing of the feed rate increases the chip volume removed per unit time [12, 24].

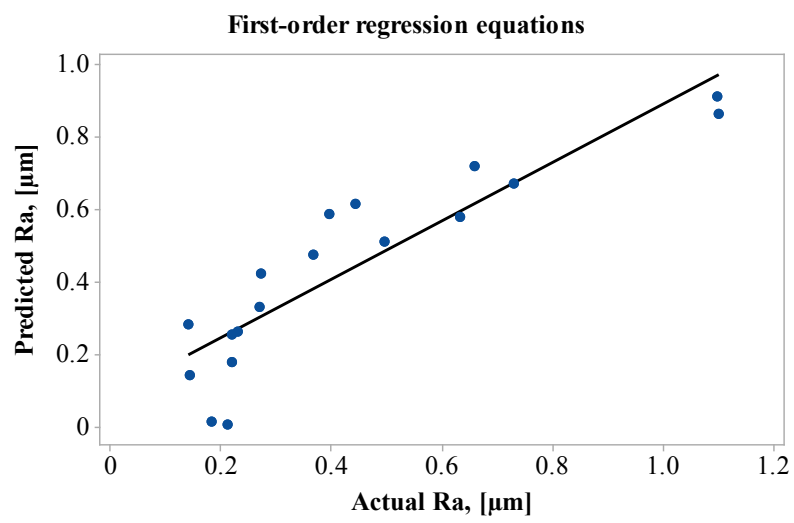

(a)

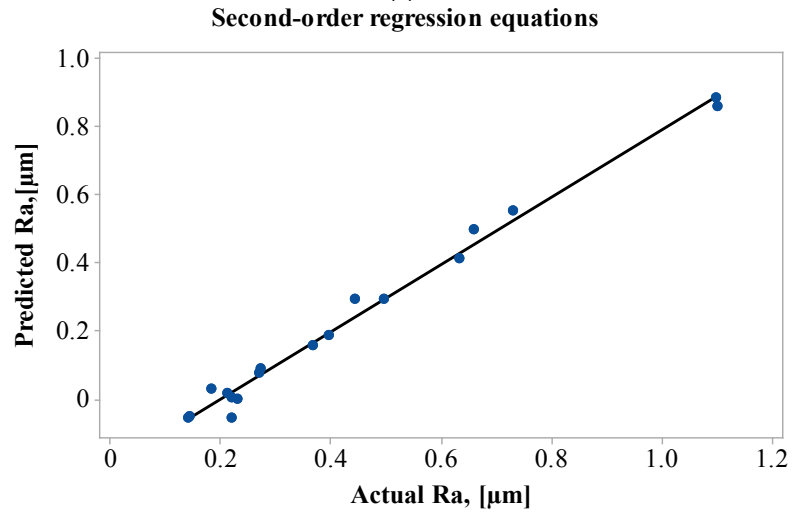

(b)

Figure 4 Comparison of the first-order and second-order regression equation with the experimental results for $R a$

\subsection{Regression Analysis}

Regression analysis is performed for the modeling and analyzing of several variables, which have the relationship between a dependent variable and one or more independent variables [25]. In this paper, the dependent variable is surface roughness $(R a)$, while the independent variables are the depth of cut $(a p)$, feed rate $(f)$, cutting speed $(V)$ and number of inserts $(N)$. The experimental test results were utilized to obtain the mathematical models by using the first-order and second-order model. The predictive equations which were acquired by using the first-order and second-order regression model of surface roughness are given below.
First-order regression equation:

$$
\begin{aligned}
& R a=-0.539+0.041 a p+4.05 f-0.000382 V+0.2760 N \\
& R^{2}=80.53
\end{aligned}
$$

\section{Second-order regression equation:}

$$
\begin{aligned}
& R a=1.665+0.100 a p-15.86 f-0.00231 V-0.725 N+ \\
& +40 f^{2}+0.000003 V^{2}+0.1026 N^{2}+2.22 a p \cdot f- \\
& -0.00054 a p \cdot V-0.066 a p \cdot N+0.00292 f \cdot V+ \\
& +4.094 f \cdot N+0.000583 \mathrm{~V} \cdot N \\
& R^{2}=98.95
\end{aligned}
$$

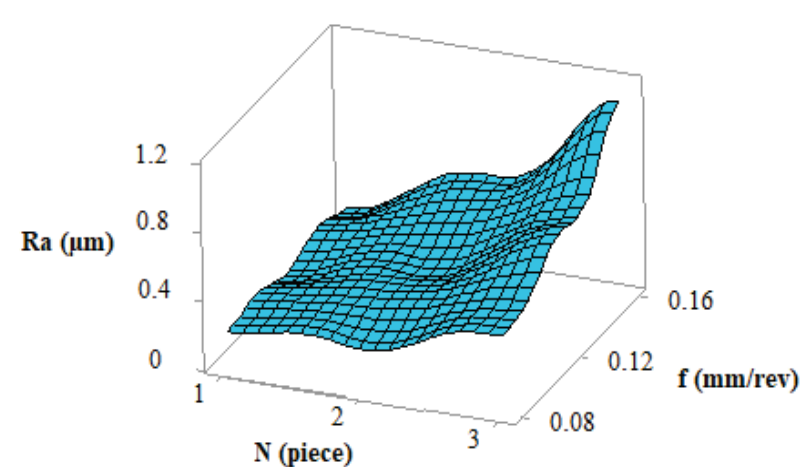

(a)

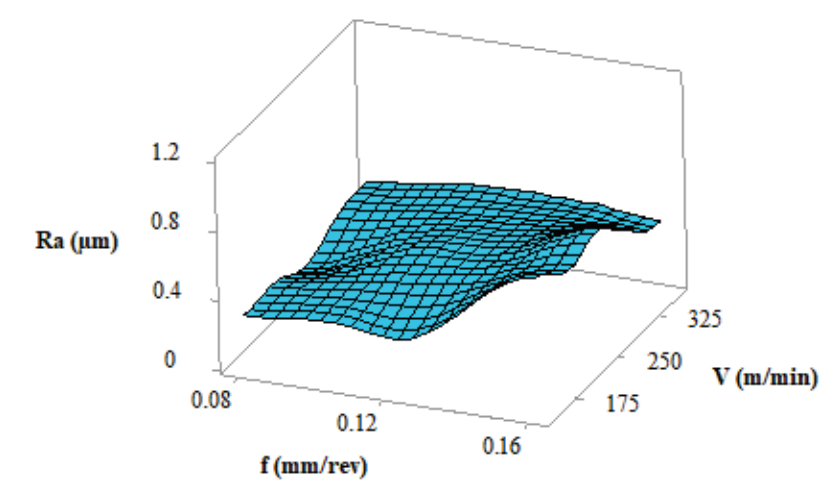

(b)

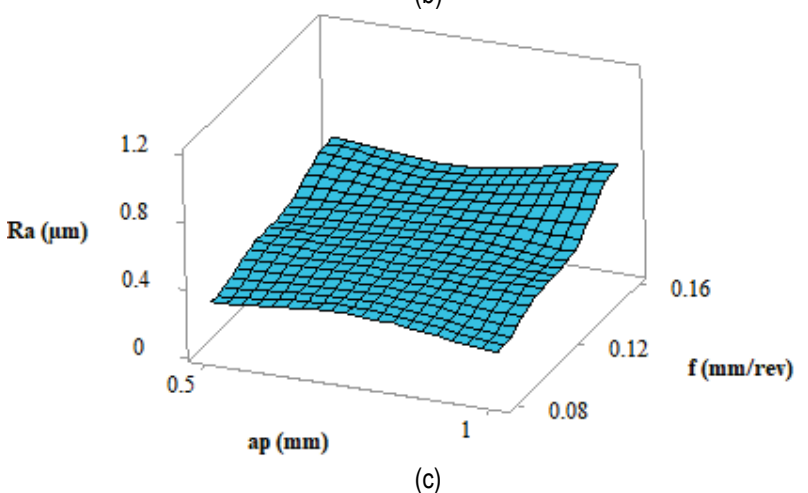

Figure $53 \mathrm{D}$ surface graphs for $R a$

The comparison of the experimental results and the predicted values which were obtained by the first-order and second-order regression model are given in Fig. 4. The correlation coefficients $\left(R^{2}\right)$ of the first-order and second- 
order regression equations that advanced for the predictive surface roughness were computed as $R^{2}=80.53 \%$ and $R^{2}=$ $98.95 \%$, respectively.

Fig. 5 shows the 3D surface graphs, which provided a Minitab 17 software for surface roughness. The relationship between the feed rate $(f)$ and number of inserts $(N)$ is shown in Fig. 5(a), the relationship between the cutting speed $(V)$ and feed rate $(f)$ is shown in Fig. 5(b) and the relationship between the feed rate $(f)$ and the depth of cut $(a p)$ is shown in Fig. 5(c). It reveals that surface roughness decreases with a reduced feed rate and with a diminished number of inserts in Fig. 5(a). Hence, a minimum level of the feed rate and a minimum number of inserts is required for minimum surface roughness. It appears that surface roughness decreases with a slight change in the cutting speed $(V)$ and with a diminished feed rate $(f)$ in Fig. 5(b). It shows that surface roughness decreases with a minimized feed rate $(f)$ and a slightly changed depth of cut $(a p)$ in Fig. 5(c).

\subsection{Confirmation Test}

Before the optimum level of control factors is chosen, the last step of the Taguchi technique approach is to estimate and confirm the development of the control factors by using the optimum level of control factors.

Factors that will be utilized to achieve the optimal $R a$ value and their levels are detected as $a p_{1} f_{1} V_{3} N_{1}$ with the aid of Tab. 3 and Fig. 3. The minimum Ra and its $S / N$ ratio that can be acquired considering these levels were computed by using the Eqs. (4) and (5). The Ra value and its $S / N$ ratio were established as $0.125 \mu \mathrm{m}$ and $18.0657 \mathrm{~dB}$ respectively.

$$
\begin{aligned}
& \eta_{G}=\eta_{m}+\sum_{i=1}^{q}\left(\bar{\eta}_{i}-\eta_{m}\right) \\
& R a_{c a l}=10^{-\frac{\eta_{G}}{20}}
\end{aligned}
$$

where $\eta_{G}$ is the $S / N$ ratio computed at the optimum levels (dB), $\eta_{m}$ is the overall average of the $S / N$ ratio, $\bar{\eta}_{i}$ is the average $\mathrm{S} / \mathrm{N}$ ratio at the optimum level, and $\mathrm{q}$ is the count of the control factors that remarkably influence the performance characteristic. Then, $R a_{c a l}$ is computed for the $R a$ value [26]. The confirmation test results were demonstrated by using the optimal control factors of surface roughness in Tab. 5.

Table 5 Confirmation test results for surface roughness

\begin{tabular}{|l|c|c|c|}
\hline \multirow{2}{*}{} & $\begin{array}{c}\text { Initial } \\
\text { machining } \\
\text { factor }\end{array}$ & Prediction & Experimental \\
\cline { 3 - 4 } & $a p_{2} f_{2} V_{2} N_{3}$ & $a p_{1} f_{1} V_{3} N_{1}$ & $a p_{1} f_{1} V_{3} N_{1}$ \\
\hline Level & 0.660 & 0.125 & 0.137 \\
\hline$R a$ & 3.6091 & 18.0657 & 17.265 \\
\hline$S / N$ ratio $(\mathrm{dB})$ & \multicolumn{4}{l}{$\mid \mathrm{N}$ ratio $13.656 \mathrm{~dB}$} \\
\hline
\end{tabular}

A comparison of the experimental results and the predicted results obtained with the Taguchi method is shown. When the predicted value of $S / N(18.0657 \mathrm{~dB})$ was compared with the actual value of $S / N(17.265 \mathrm{~dB})$ in the optimum level of control factors, a relatively good agreement was found. The enhancement of the $S / N$ ratio from the initial machining parameters to the optimum machining parameters is $13.656 \mathrm{~dB}$. The confirmation test results noticed that the surface roughness decreased 4.81 times.

\section{CONCLUSIONS}

In this research, the effect of the feed rate, cutting speed, depth of cut and number of inserts on the surface roughness in the milling process of the AISI 4140 steel with TiAlN+TiN were analyzed. The PVD coated carbide insert was performed and researched by using the Taguchi design technique. The main results were as follows:

- To optimize surface roughness Taguchi's $\mathrm{S} / \mathrm{N}$ value was employed. The effect of machining parameters on the performance characteristic was investigated by the analysis of variance. From signal to noise ratio analysis was employed. It was concluded that the optimum values for minimizing surface roughness were $0.5 \mathrm{~mm}$ for the depth of cut, $0.08 \mathrm{~mm} / \mathrm{rev}$ for the feed rate. 325 $\mathrm{m} / \mathrm{min}$ for the cutting speed and 1 for the number of inserts.

- The acquired results showed that the number of inserts was detected to be an effective factor among the controllable factors on surface roughness, followed by feed rate. However, the depth of cut and cutting speed proved to have an insignificant effect.

- The predictive models of surface roughness were also established by using the regression analysis.

- It was indicated that the experimental and regression analysis results could be effectively used for the estimation of surface roughness in the milling process of the AISI 4140 steel.

- The Taguchi design method was an effective method for the modeling and optimizing of surface roughness in the milling process.

- The development of surface roughness from the initial machining parameters to the optimal machining parameter is about $481 \%$.

- In the manufacturing engineering applications, the Taguchi design technique and regression analysis were able to supply the minimum cost and time.

\section{REFERENCES}

[1] Sahare, S. B., et al. (2018). Optimization of End Milling Process for A12024-T4 Aluminum by Combined Taguchi and Artificial Neural Network Process. Soft Computing: Theories and Applications, Springer, 525-535. https://doi.org/10.1007/978-981-10-5699-4_49

[2] Lou, M. S., Chen, J. C., \& Li, C. M. (1998). Surface roughness prediction technique for CNC end-milling. Journal of Industrial Technology, 15(1), 1-6.

[3] Kahraman, F. (2009). The use of response surface methodology for prediction and analysis of surface roughness of AISI 4140 steel. Materiali in Tehnologije, 43(5), 267-270.

[4] Sahin, Y. \& Motorcu, A. (2008). Surface roughness model in machining hardened steel with cubic boron nitride cutting 
tool. International Journal of Refractory Metals and Hard Materials, 26(2), 84-90. https://doi.org/10.1016/j.ijrmhm.2007.02.005

[5] Pop, A. B. \& Aurel, T. M. (2017). Optimization of the Surface Roughness Equation obtained by Al7136 EndMilling. MATEC Web of Conferences. EDP Sciences. https://doi.org/10.1051/matecconf/201713703011

[6] Pop, A. B. B. (2014). Investigating the effect of machining parameters on surface roughness of 7136 aluminum alloy in end milling. Scientific Bulletin Series C: Fascicle Mechanics, Tribology, Machine Manufacturing Technology, 28, 12.

[7] Stipkovic Filho, M., et al. (2018). Experimental Numerical Model of Roughness in Finishing Face Milling of AISI 4140 Hardened Steel. Improved Performance of Materials., Springer, 83-91. https://doi.org/10.1007/978-3-319-59590-0_8

[8] Ventura, C. E., et al. (2017). The influence of the cutting tool microgeometry on the machinability of hardened AISI 4140 steel. The International Journal of Advanced Manufacturing Technology, 1-9. https://doi.org/10.1007/s00170-016-9582-4

[9] Sales, W., et al. (2009). Tribological behaviour when face milling AISI 4140 steel with minimum quantity fluid application. Industrial Lubrication and Tribology, 61(2), 8490. https://doi.org/10.1108/00368790910940400

[10] Özek, C., Çaydaş, U., \& Ünal, E. (2012). A fuzzy model for predicting surface roughness in plasma arc cutting of AISI 4140 steel. Materials and Manufacturing Processes, 27(1), 95-102. https://doi.org/10.1080/10426914.2011.551952

[11] Parametrov, U. T. M. Z. O. (2017). Optimization of the Machining Parameters for the Turning of 15-5 Ph Stainless Steels Using the Taguchi Method. Optimization, 133, 140.

[12] Sarıkaya, M., Dilipak, H., \& Gezgin, A. (2015). Optimization of Process Parameters for Surface Roughness and Tool Life in Face Milling using the Taguchi Analysis.

[13] Motorcu, A. R., et al. (2016). Analysis of the Cutting Temperature and Surface Roughness during the Orthogonal Machining of Aisi 4140 Alloy Steel via the Taguchi Method. Analysis, 343, 351. https://doi.org/10.17222/mit.2015.021

[14] Motorcu, A. R., Ekici, E., \& Kuş, A. (2016). Investigation of the WEDM of $\mathrm{Al} / \mathrm{B} 4 \mathrm{C} / \mathrm{Gr}$ reinforced hybrid composites using the Taguchi method and response surface methodology. Science and Engineering of Composite Materials, 23(4), 435445.

[15] Gupta, M. K. \& Sood, P. K. (2016). Optimizing Multi Characterstics in Machining of AISI 4340 Steel Using Taguchi's Approach and Utility Concept. Journal of the Institution of Engineers (India): Series C, 97(1), 63-69. https://doi.org/10.1007/s40032-015-0201-1

[16] Kivak, T. (2014). Optimization of surface roughness and flank wear using the Taguchi method in milling of Hadfield steel with PVD and CVD coated inserts. Measurement, 50, 19-28. https://doi.org/10.1016/j.measurement.2013.12.017

[17] Ekici, E., Motorcu, A. R., \& Kuş, A. (2016). Evaluation of surface roughness and material removal rate in the wire electrical discharge machining of $\mathrm{Al} / \mathrm{B} 4 \mathrm{C}$ composites via the Taguchi method. Journal of Composite Materials, 50(18), 2575-2586. https://doi.org/10.1177/0021998315609788

[18] Boy, M., et al. (2015). Application of the Taguchi Method to Optimize the Cutting Conditions in Hard Turning of a Ring Bore. Materiali in Tehnologije, 49(5), 765-772. https://doi.org/10.17222/mit.2014.246

[19] Günay, M. \& Yücel, E. (2013). Application of Taguchi method for determining optimum surface roughness in turning of high-alloy white cast iron. Measurement, 46(2), 913-919. https://doi.org/10.1016/j.measurement.2012.10.013
[20] Asiltürk, I. \& Akkuş, H. (2011). Determining the effect of cutting parameters on surface roughness in hard turning using the Taguchi method. Measurement, 44(9), 1697-1704. https://doi.org/10.1016/j.measurement.2011.07.003

[21] Mandal, N., et al. (2011). Optimization of flank wear using Zirconia Toughened Alumina (ZTA) cutting tool: Taguchi method and Regression analysis. Measurement, 44(10), 21492155. https://doi.org/10.1016/j.measurement.2011.07.022

[22] Çakıroğlu, R. \& Acır, A. (2013). Optimization of cutting parameters on drill bit temperature in drilling by Taguchi method. Measurement, 46(9), 3525-3531. https://doi.org/10.1016/j.measurement.2013.06.046

[23] Yang, W. P. \& Tarng, Y. (1998). Design optimization of cutting parameters for turning operations based on the Taguchi method. Journal of Materials Processing Technology, 84(1), 122-129. https://doi.org/10.1016/S0924-0136(98)00079-X

[24] Kıvak, T., Samtaş, G., \& Cicek, A. (2012). Taguchi method based optimisation of drilling parameters in drilling of AISI 316 steel with PVD monolayer and multilayer coated HSS drills. Measurement, 45(6), 1547-1557. https://doi.org/10.1016/j.measurement.2012.02.022

[25] Cetin, M. H., et al. (2011). Evaluation of vegetable based cutting fluids with extreme pressure and cutting parameters in turning of AISI 304L by Taguchi method. Journal of Cleaner Production, 19(17), 2049-2056. https://doi.org/10.1016/j.jclepro.2011.07.013

[26] Gologlu, C. \& Sakarya, N. (2008). The effects of cutter path strategies on surface roughness of pocket milling of 1.2738 steel based on Taguchi method. Journal of Materials Processing Technology, 206(1), 7-15. https://doi.org/10.1016/j.jmatprotec.2007.11.300

\section{Authors' contacts: \\ Gokhan BASAR, Research Assistant \\ Osmaniye Korkut Ata University, \\ Department of Manufacturing Engineering, \\ 80000 , Osmaniye, Turkey \\ E-mail: gokhanbasar@osmaniye.edu.tr}

Hediye KIRLI AKIN, Assistant Professor, PhD

Corresponding author

Osmaniye Korkut Ata University,

Department of Manufacturing Engineering,

80000 , Osmaniye, Turkey

E-mail: hediyeakin@osmaniye.edu.tr

Funda KAHRAMAN, Associate Professor, PhD

Mersin University,

Department of Mechatronics Engineering,

33400 , Mersin, Turkey

E-mail: fkahraman@mersin.edu.tr

Yusuf FEDAl, Assistant Professor, PhD

Osmaniye Korkut Ata University,

Department of Manufacturing Engineering,

80000 , Osmaniye, Turkey

E-mail: yusuffedai@osmaniye.edu.tr 